\title{
Memoria de internacionalistas chilenos. Entramado conceptual y recuperación histórica. Apuntes para el debate
}

\author{
Memory of Chilean internationalists. Conceptual framing and historical \\ recovery. Notes for the debate
}

\author{
Pedro Valdés Navarro *
}

\begin{abstract}
Resumen: El presente artículo, rescata la memoria de cuatro chilenos, que se vincularon con organizaciones revolucionarias en el extranjero y que desarrollaron un trabajo político bajo la visión del Internacionalismo militante. El testimonio de los entrevistados, es la puerta de entrada que nos permite deambular por los márgenes de un fenómeno amplio y de largo alcance como lo es el Internacionalismo. Una vez allí, pretendemos identificar los componentes teóricos que lo entrelazan, y evidenciar la existencia de otras experiencias internacionalistas que van más allá de las estudiadas por la historiografía reciente, a saber, el derrotero de chilenos comunistas entrenados en Cuba y que participaron en la guerrilla sandinista. Nuestro foco estuvo direccionado en la historia de miristas, socialistas y mapucistas, que practicaron el internacionalismo en Bolivia, Perú, Nicaragua y Argentina.
\end{abstract}

Palabras clave: Internacionalismo, Izquierdas, Militancia, Memoria

\begin{abstract}
This article rescues the memory of four Chileans, who were linked to revolutionary organizations abroad and who developed a political work under the vision of militant Internationalism. The testimony of the interviewees is the gateway that allows us to wander the margins of a broad and far-reaching phenomenon such as Internationalism. Once there, we try to identify the theoretical components that interweave it, and to show the existence of other internationalist experiences that go beyond those studied by recent historiography, namely, the course of Communist Chileans trained in Cuba and who participated in the guerrilla Sandinista. Our focus was on the history of miristas, socialists and mapucistas, who practiced internationalism in Bolivia, Peru, Nicaragua and Argentina.
\end{abstract}

Keywords: Internationalism, Left, Militant, Memory

Recibido: 9 junio 2017

Aceptado: 30 agosto 2017

${ }^{*}$ Chileno. Licenciado en Historia, Universidad de Valparaíso. Magister en Historia, USACH. Diplomado en Estudios Latinoamericanos, U. de Chile. Este trabajo fue presentado como ponencia en el XII Encuentro Nacional, VI Congreso Internacional de Historia Oral de Argentina, 5 al 8 de octubre de 2016, Tucumán. Agradezco los comentarios y sugerencias de Gustavo Cortés Navarro y de Oscar Pavetti, de la Universidad Nacional de Tucumán. Correo electrónico; pedroalfonsovaldes@gmail.com 


\section{Presentación}

Las estrenadas investigaciones, estudios, autobiografías sobre la historia reciente de Chile, reabre nuevamente el interés por develar las complejidades de la memoria política de nuestro país, y las raíces de nuestra actual contingencia. Como señala el militante internacionalista José Miguel Carrera, en sus memorias, "No se conoce en Chile la historia de los internacionalistas...no quiero que el tiempo pase y que la muerte silencie las vivencias que compartí con mis hermanos internacionalistas. Este es mi único propósito"2. En la presentación de su libro, Javiera Olivares nos plantea la urgencia de rescatar la identidad de aquellos que combatieron por la construcción de una sociedad más justa y equitativa. Estos eran antiguos combatientes comunistas que entregaron sus vidas por la libertad de otros. Ameritaba, como plantea Olivares, un acto de justicia. Se retomaba la historia de los chilenos internacionalistas que empuñaron las armas en suelo nicaragüense, salvadoreño y colombiano. El objetivo de la autora es “....rescatar desde el espectro de lo invisible parte de nuestra historia, a través de los testimonios de un puñado de jóvenes comunistas chilenos que integraron las últimas generaciones que se prepararon en países socialistas para buscar una salida revolucionaria a la dictadura de Pinochet" 3 . Quedaba, y queda aún en evidencia, la relevancia de esta zona oscura de nuestro pasado.

Si bien la temática no deja de tener el interés que amerita conocer las experiencias de lucha en otros países de hombres y mujeres, el fenómeno del internacionalismo, en la mayoría de los últimos estudios, está tratado desde una perspectiva testimonial y unívoca. Testimonial en el sentido de que las investigaciones de historiadores y periodistas que se han preocupado por el tema, lo han hecho tomando como eje central los relatos de los combatientes, la memoria militante de aquellos y aquellas que protagonizaron la historia. Estos relatos, evidenciados en el Chile de la post dictadura, no salen a flote solos ni cuentan su propia historia individual. Vienen con ellos los vestigios históricos, personales, familiares, que acompañan al internacionalista en su redescubrimiento político. Como señala Elizabeth Jelin, es importante entender que,

Las memorias individuales están siempre enmarcadas socialmente. Estos marcos son portadores de la representación general de la sociedad, de sus necesidades y valores. Incluyen también la visión del mundo, animada por valores, de una sociedad o grupo ${ }^{4}$.

Los estudios sobre este fenómeno, en nuestra historiografía reciente, se han enfocado mayoritariamente en profundizar determinadas experiencias internacionalistas,

\footnotetext{
2 José Miguel Carrera Carmona. Misión Internacionalista. De una población chilena a la revolución sandinista, Santiago, Editorial Latinoamericana, 2010, pp: 9.

3 Javiera Olivares Mardones. Guerrilla. Combatientes chilenos en Colombia, El Salvador y Nicaragua. Santiago, Ceibo ediciones, 2017, pp: 19.

${ }^{4}$ Elizabeth Jelin. Los trabajos de la Memoria. Madrid, Siglo XXI editores, 2002, pp: 20.
} 
dejando de lado, creemos que ha sido una decisión metodológica más que una ausencia teórica, la profundización sobre el concepto mismo. Dicho de otra forma, las investigaciones se han direccionado en torno a los internacionalistas más que al internacionalismo. Pretendemos, también desde lo acotado de este espacio, enunciar algunas ideas, reflexiones y rescates necesarios en torno a este fenómeno histórico, antes de hablar sobre los sujetos mismos. Creemos que el internacionalismo tiene una trayectoria histórica, que es importante enunciar para tener en contexto el relato sobre las vivencias de sus protagonistas.

Y en segundo lugar, lo unívoco del tratamiento del fenómeno, se relaciona con la aparición de un tipo de experiencia internacionalista. La de jóvenes comunistas que tempranamente comenzaron a recibir instrucción militar en las bases cubanas, y que posteriormente iniciaron su prueba de fuego como artilleros en la fase final de la guerrilla sandinista en Nicaragua. Como señalan varios historiadores, esta decisión se dio al interior del PC, luego de una larga discusión teórica y política, en torno al rol de lo militar en la estrategia de los comunistas chilenos, lo que implicaba, para ese entonces y dadas las características que estaba asumiendo la dictadura de Pinochet, reconfigurar la inicial estrategia de articulación de un frente antifascista en el cual podían formar parte todos los sectores opositores al régimen dictatorial, y asumir un giro histórico en donde empezara a tomar forma la adopción de una fuerza militar propia del partido encaminada a debilitar y erosionar las bases del sistema autoritario pinochetista ${ }^{5}$.

Este periplo es el que más ha llamado la atención de investigadores, y por el cual también han escrito sus memorias distintos sobrevivientes. Los inaugurales trabajos de Viviana Bravo y Rolando Álvarez, representan uno de los primeros acercamientos hacia el tema $^{6}$. Más adelante, aparece uno de los primeros libros sobre la experiencia de chilenos en la revolución sandinista que está acompañado de un enriquecedor registro fotográfico. Es la investigación de Pascale Bonnefoy, Claudio Pérez y Ángel Spotorno ${ }^{7}$. En un detallado análisis de los antecedentes de la historia política y militar del PC y del FPMR, Luis Rojas Núñez también aporta a la experiencia comunista en Nicaragua ${ }^{8}$. Ampliando las experiencias, Cristián Pérez publicó en 2012 en la revista de Estudios Públicos, un estudio sobre lo anterior ${ }^{9}$. Por otra parte, las memorias de los sobrevivientes también han ocupado los espacios editoriales, entre las que se encuentran las del militante comunista José Miguel

\footnotetext{
${ }^{5}$ Sobre este punto ver entre otros; Claudio Pérez. "De la guerra contra Somoza a la guerra contra Pinochet. La experiencia internacionalista revolucionaria en Nicaragua y la construcción de la Fuerza Militar Propia del Partido Comunista de Chile”. En: Historia oral e Historia política. Izquierda y lucha armada en América Latina, 1960-1990. Santiago, LOM, 2012.

${ }^{6}$ Rolando Álvarez. Viviana Bravo. "La memoria de las armas. Para una historia de los combatientes chilenos en Nicaragua”, En; Revista Lucha Armada en la Argentina, № 5, Argentina, 2006.

7 Pascale Bonnefoy. Claudio Pérez. Ángel Spotorno. Internacionalistas, chilenos en la revolución popular sandinista. Santiago, Editorial Latinoamericana, 2009.

${ }^{8}$ Luis Rojas Núñez. De la rebelión popular a la sublevación imaginada. Santiago, LOM, 2011.

${ }^{9}$ Cristián Pérez. "Compañeros, a las armas: combatientes chilenos en Centroamérica (1979-1989)". En: Estudios Públicos, $\mathrm{N}^{\circ} 129$, verano 2013, Santiago, CEP.
} 
Carrera, y el reciente libro de Manuel Cortés, militante socialista, ambos sobrevivientes de la revolución sandinista ${ }^{10}$.

Este aceptable número de memorias e investigaciones, ensombrecía la evidencia de otros internacionalismos. De otras experiencias de vínculos con la lucha armada y con el proyecto de construcción social en otras tierras que no fuera la chilena. Es desde este espacio de discusión que pretendemos ampliar el fenómeno hacia otras memorias. De aquellas y aquellos chilenos que no militaron en el PC chileno y que se insertaron en un proyecto político de liberación en otras espacios del continente ${ }^{11}$. El propósito es complejizar aún más este nicho historiográfico. Es válido poder preguntarse ¿Qué características diferenciadoras asumieron estas experiencias internacionalistas? Es importante plantear que las historias vividas por estos militantes, se desarrollaron sin un soporte político seguro, no tuvieron una red amplia de apoyo logístico, fueron las pericias individuales y los pocos núcleos de ayuda los que les permitieron sobrevivir primeramente y luego insertarse en las dinámicas internacionalistas. ¿Qué elementos comunes poseen estas vivencias de lucha en el extranjero y como la experiencia moldeo su visión política?

Se edifican entonces nudos críticos que sustentan parte de su militancia. Algo así como una red conceptual tejida de forma natural, en la cual se van anidando los relatos del pasado. Sabemos que el desafío es grande, pero no pretendemos abarcar la totalidad de la discusión, sino más bien evidenciar la posibilidad de extender la discusión sobre el tema.

\section{Sobre el Internacionalismo}

Ya se habla de Internacionalismo cuando el movimiento obrero europeo de mediados del siglo XIX, fundamentalmente, empieza a edificar un proyecto de organización supranacional. Nos referimos a la materialización de la Asociación Internacional de Trabajadores, más conocida como la Primera Internacional. El fruto de este proceso estuvo enmarcado en la condensación y proliferación de los movimientos nacionalistas de mediados del siglo XIX en la Europa pos revolucionaria. Así, a la concreción de los estados-nacionales de corte burgués nacionalista, se opuso la intención de obreros y trabajadores de condensar un proyecto socialista de con características internacionalista. Como manifiesta Eric Hobsbawm, en la década de 1860 nos encontramos frente a la reaparición de un movimiento obrero europeo revitalizado y reforzado, que contenía una serie de variadas demandas locales y específicas, pero por sobre todo

...era internacional, y no sólo porque, al igual que el reavivamiento del liberalismo, sucedió simultáneamente en varios países, sino por su

\footnotetext{
${ }_{10}$ José Miguel Carrera, Op Cit. Manuel Cortés. Arnaldo Pérez, Yo Patán, memorias de un combatiente, Santiago, Ceibo ediciones, 2015.

${ }^{11}$ Los militantes entrevistados aparecen con su nombre de pila. En algunos casos se agrega además su nombre político, el que está escrito en cursiva.
} 
condición de inseparable solidaridad internacional de las clases obreras, o de la solidaridad internacional de la izquierda radical. Se organizó realmente cómo y por la asociación internacional de trabajadores, la primera internacional de Karl Marx...Para todos los radicales los triunfos y derrotas de la izquierda en cualquier lugar del mundo parecían tener que ver aún con ellos inmediata y directamente ${ }^{12}$.

En estricto rigor entonces hablamos de Internacionalismo cuando una organización, movimiento o un grupo de militantes asume la tarea de vincularse con proyectos políticos en otros territorios, en otras fronteras, bajo la perspectiva teórica de que, para reemplazar al modelo dominante capitalista, es necesario en cualquier lugar del planeta, avanzar en la construcción del socialismo, enfrentándose con éste mediante la utilización de la violencia revolucionaria. Cabe destacar que aquellos militantes, hombres y mujeres que se vincularon con los proyectos revolucionarios en el extranjero, ya sea en el lugar mismo de la contienda o desde miles de kilómetros de distancia, y desarrollaron labores de apoyo logístico, enlaces de comunicación, recaudación de fondos económicos, trabajo médico, solidaridad desde sus trincheras culturales, y un sinfín de múltiples acciones en pos de colaborar con estos movimientos, también forman parte (podemos recalcar que desde un circulo más periférico) de esta concepción Internacionalista. Bajo esta colaboración intencionada y direccionada, estaba la concepción de que la lucha contra el modelo dominante no tenía fronteras territoriales.

No obstante, es necesario precisar los alcances de este fenómeno. No cualquier colaboración de clase o entre sujetos populares, representa necesariamente una lucha internacionalista. A lo largo de la Historia, nos encontramos con diversos ejemplos de colaboración entre los oprimidos; la rebelión de esclavos liderada por Espartaco en el siglo I a.c. en contra del poder romano, en donde se produjo la unión de los desclasados provenientes de distintas zonas de la república romana. O las sublevaciones de los campesinos pobres franceses de fines de la Europa Medieval en contra del poder de los grandes señores feudales, que generó una solidaridad de sus pares de otras zonas empobrecidas. No obstante, en este sentido, estas luchas solidarias son manifestaciones premodernas de colaboración entre sujetos de una misma condición social, en contra de un poder dominante. El componente político, lo van a adquirir cuando estas manifestaciones sociales, busquen además una transformación política, y esa visión estructural se edificó en el siglo XIX bajo el alero del socialismo. Cabe mencionar, que la mayoría de los testimonios, y de las investigaciones en torno al tema, en nuestro continente, mencionan como pasado épico, las luchas por la emancipación de América, las gestas de los libertadores criollos, son los antecesores de la colaboración latinoamericanista, los que aparecen como parte de la raíz, de la matriz que nutre el largo proceso por la liberación. En otro sentido, creemos que la práctica internacionalista, no estuvo circunscrita exclusivamente a la tarea militar en el frente, sino que también, fueron parte de esta lógica, de esta visión, todos aquellos y aquellas que se involucraron de distintas formas, y en

${ }^{12}$ Eric Hobsbawm. La Era del Capital, 1848-1875, Buenos Aires, Crítica, 1998, pp: 120. 
variadas tareas, en el objetivo transnacional de emancipación. No es sólo el plano militar, el que le dio cuerpo al fenómeno, sino que una amplia gama de tareas cumplidas en forma sigilosa y clandestina por los internacionalistas.

Si bien se reconoce en el Marxismo, la compaginación de una argumentación que dé pie al Internacionalismo Proletario, a partir de 1848 con el Manifiesto Comunista, fueron los mismos autores de este programa los que destacaron los primeros aportes de Flora Tristán, pensadora francesa de la primera mitad del siglo XIX, que ya en 1840 en su escrito "La Unión Obrera" abogaba por la necesaria concatenación de clase. En este sentido Tristán señala, "Yo vengo a proponeros una unión general de los obreros y obreras, sin distinción de oficios que vivan en el mismo reino; una unión que tendría por objetivo construir la clase obrera". Y más adelante agrega. "La unión obrera, procedimiento en nombre de la Unidad Universal, no debe hacer ninguna distinción entre los obreros nacionales y los obreros y obreras pertenecientes a no importa que nación de la tierra". ${ }^{13}$ Esta contribución vino a condensar lo que Marx y Engels estructuraron en el Manifiesto, donde explicitan la esencia Internacionalista del Socialismo y condición sine qua non de su lucha política. La frase célebre de "Proletarios de todos los países uníos", va precedida de una contextualización, que va más allá del corolario de una consigna. Los autores señalan, "En suma, los comunistas apoyan dondequiera todo movimiento revolucionario contra las condiciones sociales y políticas existentes...por último, los comunistas trabajan en todas partes por la unión y el entendimiento entre los partidos democráticos de todos los países". ${ }^{14}$ Esta doble faceta que muestra la simpleza del argumento, pero a la vez la complejidad del tema, vino a enriquecerse discursivamente con el cambio de escenario que significaron los triunfos del socialismo en el siglo XX. Tanto la Revolución Rusa como la Revolución Cubana entendieron la necesidad de la expansión de sus proyectos específicos, hacia la apertura de una confrontación continental. Y para esto, ambos bastiones, la URSS primero y luego Cuba, se transformaron en centros de fortalecimiento, empuje y difusión del Internacionalismo.

Para el caso cubano, el aporte y reforzamiento teórico de éste fenómeno, vino sin lugar a dudas a través de la iniciativa de Ernesto Che Guevara. Son múltiples los discursos, ensayos y argumentos que el médico argentino-cubano evidenció en torno a la necesidad de convertir la lucha contra Batista en una lucha por el socialismo a nivel continental. En una de sus últimas apariciones públicas, y ya con el proyecto de revolución mundial en la mente y espíritu, el Che afirma ante los líderes políticos del mundo, la vigencia de los postulados

\footnotetext{
${ }^{13}$ Flora Tristán, Unión Obrera, En: Colección Socialismo y Libertad, Edición Digital, El Sudamericano, 2016, pp: 25, 63.

${ }^{14}$ Carlos Marx. Federico Engels, Manifiesto Comunista, Santiago, Editorial Universitaria de Chile, 1970, pp: 69. Marx, y posiblemente también Engels, venían ya elaborando esta idea, estimulada por la fuerte presencia de las luchas nacionalistas de la época. En su carta a Proudhon fechada en mayo de 1846, le señala: "De esta manera, las diferencias de opinión se podrán manifestar; se llegará a un cambio de ideas y a una crítica imparcial. He aquí un paso que había dado el movimiento social en su expresión "literaria", a fin de liberarse de los límites de la "nacionalidad". Y, en el momento de la acción, es ciertamente de un gran interés para cada uno estar informado del estado de cosas en el extranjero como en su casa". En: Ernst Mandel, Karl Marx a Proudhon, Sobre la historia del movimiento obrero, Barcelona, Editorial Fontamara, 1978, pp:21.
} 
marxistas y la unión entre la construcción de un modelo social alternativo y la solidaridad proletaria. En este sentido el Che señala,

No hay fronteras en esta lucha a muerte, no podemos permanecer indiferentes frente a lo que ocurre en cualquier parte del mundo, una victoria de cualquier país sobre el imperialismo es una victoria nuestra, así como la derrota de una nación cualquiera es una derrota para todos. El ejercicio del internacionalismo proletario es no sólo un deber de los pueblos que luchan por asegurar un futuro mejor; además, es una necesidad insoslayable ${ }^{15}$.

Como hemos podido evidenciar, la solidaridad internacional enmarcada dentro de la lógica socialista, de la defensa de la democracia y de las libertades conquistadas, tiene un largo bagaje teórico que sustentaron las luchas por la construcción de un modelo social distinto al dominante o, en su defecto, por la defensa en contra de la agresión de una ideología que buscaba la sustitución del socialismo, como por ejemplo, el fascismo. En este sentido, la coyuntura que mejor reflejó este movimiento internacionalista, fue la Guerra Civil Española.

\section{Experiencias internacionalistas. Desde la Brigadas Internacionalistas hasta la lucha de militantes en Centroamérica}

Como menciona Manuel Requena Gallego, la maquinaria montada para acudir en pos de la defensa armada de la República española, contó con el auspicio inicial de la dirigencia soviética y constituyó uno de los episodios más emblemático de la lucha en contra del avance del fascismo. El autor se refiere de la siguiente manera,

Estos constituyeron un ejército internacional, único en la historia por su número y su carácter voluntario, no mercenario, que combatió como fuerza de choque en la mayoría de las batallas de la Guerra Civil española. Procedían de más de 50 países y contribuyeron a la defensa de la Segunda República, no sólo en el aspecto militar, sino también como un ejemplo de solidaridad internacional ${ }^{16}$.

\footnotetext{
${ }^{15}$ Ernesto Che Guevara, "Discurso de Argel, Argelia 24 de febrero de 1965", En la Conferencia Afroasiática en Argelia, México, Editorial Ocean SUR, 2001, pp: 5.

${ }^{16}$ Manuel Requena Gallego, "Las Brigadas Internacionales: una aproximación historiográfica”. Ayer $\mathrm{N}^{\circ} 56$, Revista de Historia Contemporánea, Madrid, 2004, pp: 12.
} 
La constatación de la delgada línea que define lo nacional, versus la patria universal de los proletarios, aparece en su máxima composición, en el episodio bélico español. La enorme estructura instalada, recaudación de voluntarios, líneas de comunicación y planificación de estas Brigadas, la dotan de un peso valórico irrepetible, por sobre el modelo militar. La entrega a los voluntarios internacionalistas de la nacionalidad española a sesenta años de la guerra, no sólo recompone la memoria histórica, sino que además actualiza la visión internacionalista como un fenómeno que trasciende lo local, para instalarse en la memoria política de la militancia de izquierda.

Dentro de este grupo de internacionalistas encontramos a los primeros chilenos que se unieron sin mediar el asegurado éxito de la empresa, bajo un contexto de álgidas disputas entre el socialismo y el fascismo ${ }^{17}$. La investigación de la historiadora Olga Ulianova, nos da cuenta del registro de numerosos compatriotas que se embarcaron más allá del Atlántico, para involucrarse en la gesta republicana. En palabras de Ulianova,

La gran sorpresa para nosotros fue el hecho de que prácticamente todos los brigadistas chilenos provenientes de Chile resultaron ser militares profesionales, oficiales activos o en retiro del Ejército y de la Armada de Chile, lo que si bien se inscribe en la atmósfera de los años cercanos a la República Socialista y otras manifestaciones de inquietudes políticas y sociales de los militares chilenos en las décadas de los '20 y ' 30 , constituye un episodio excepcional ${ }^{18}$.

Algunos de estos militares tenían militancia comunista como, Miguel Álvarez Torres, ex oficial de la Armada, Manuel Cerda Muñoz, Luis Moren Herrera, ambos soldados del Ejército. Había otros socialistas como Luis Ángel Zendolla, capitán de aviación, Alejandro Martínez, Gustavo Gaete, Raúl Galleguillos Molina, Salustino Herrera Jarpa, quien llegó a ser jefe del Estado Mayor del Ejército Popular. Francisco Marín, Rubén Soto, Luis Uribe Castro y Ernesto Villarroel completan la lista.

${ }^{17}$ Es importante rescatar la memoria de chilenos, trece en total, que fueron a pelear por la independencia cubana a fines del siglo XIX. Es reconocido el ejemplo del marino Pedro Vargas Sotomayor, cercano a Antonio Maceo, quien alcanzó el grado de general de las tropas cubanas. No obstante, este modelo de solidaridad internacional, probablemente el primero de nuestros compatriotas, se escapa de la lógica internacionalista que venimos desarrollando. Amparada ésta no solamente en la colaboración más allá de las fronteras nacionales, sino que sustentada por la defensa o instalación del socialismo en sus distintas vertientes. Para más detalles sobre Pedro Vargas Sotomayor, ver. Raúl Mesa García. "El general chileno Pedro Vargas Sotomayor: maestro de mambises", Revista Sudhistoria, N 3, julio-diciembre, Valdivia, Universidad Austral de Chile, 2011.

18 Olga Ulianova. "A sesenta años de la guerra civil española. Combatientes chilenos en las brigadas internacionales", Revista de Estudios Avanzados, Volumen 5, N7, IDEA-USACH, Santiago, 2006, p: 3. Olga Ulianova comenta que junto con las investigaciones de Gerold Gino Baumann, es posible encontrar cerca de sesenta chilenos, o hijos de chilenos que pelaron en la Guerra Civil Española, siendo un número considerable dentro del contingente Latinoamericano. 
Si bien estos ejemplos, casi anónimos e invisibilizados, forman parte de la memoria colectiva de la historia española, la historiografía chilena reciente se ha enfocado con justicia y aún con lentitud, en recobrar la experiencia de parte de las vivencias de militantes en su mayoría comunistas, que bajo un contexto muy distinto y distante al de la década de los treinta, se embarcaron con el auspicio de una Cuba revolucionaria en un proyecto continental de lucha, entendiendo que la utilización de la violencia política era el único camino posible para la instauración de una sociedad más justa y libre. Nos referimos al internacionalismo de comunistas chilenos en la revolución sandinista.

No es nuestro propósito, por espacio y profundidad, explayarnos en torno a la revisión de estos estudios, sí nos parece necesario combinar el comentario sobre lo más significativo en materia de investigación histórica y las experiencias todavía no sistematizadas y que aparecen como relatos sueltos y merecidos, de colectivos de memorias que buscan rescatar a sus amigos y familiares del olvido.

Tal como plantean los historiadores Pablo Pozzi y Claudio Pérez, el período comprendido entre 1960 y 1980, fue protagonizado por toda una generación de jóvenes en su mayoría, que se involucró en el sendero de la revolución social, caracterizando a la larga década de los sesenta, como un ciclo denso de la historia Latinoamericana en donde numerosos grupos guerrilleros y un sinnúmero de organización político-militares, instalaron el problema de la violencia política como un eje problemático y estructural de las sociedades del continente. Según Pozzi y Pérez,

...el siglo XX latinoamericano se caracterizó por una relación dinámica y dialéctica entre la izquierda y los movimientos sociales e intelectuales. Y asimismo, que una cantidad de fenómenos históricos de nuestro continente son incomprensibles sin profundizar en este tema. De ahí que nos interese estudiar la experiencia de la izquierda revolucionaria, sus organizaciones y expresiones político-militares, comprender en profundidad su historia, significado y la sociedad que las gestó ${ }^{19}$.

Este marco histórico es el que cubrió y nutrió las experiencias de chilenos en la Revolución nicaragüense. Gestada con un nivel de preparación inédita en la historia política, este fenómeno tuvo como eje de partida, la iniciativa de la dirección cubana en contribuir en la formación de cuadros militares chilenos que llenaran el vacio militar que había en parte importante de la izquierda chilena, evidencia que aparecía luego de la derrota de la UP. En específico dentro del PC, esta empresa, como plantean Viviana Bravo y Rolando Álvarez, hay que entenderla en la estrategia general diseñada por los comunistas chilenos a mediados de los setenta, que dieron un giro copernicano en relación a la tradicional lógica política enmarcada en los espacios institucionales. La nueva política

${ }^{19}$ Pablo Pozzi, Claudio Pérez (ed.). Historia oral e Historia política. Izquierda y lucha armada en América Latina, 1960-1990. Santiago, LOM, 2012, pp: 10. 
instalaba la concepción de que "todas las formas posibles de lucha servirían" para derrotar a la dictadura ${ }^{20}$.

El grueso del contingente de combatientes que iniciaron su participación en la guerrilla nicaragüense pertenecían a las filas del PC chileno, formados en la especialidad de artillería, ingresaron a la lucha a mediados de 1979. No obstante, esta línea histórica no fue la única seguida por los internacionalistas chilenos. Fueron diversas oleadas de chilenos los que partieron a las academias de formación militar isleña. Los autores comentan, "En marzo de 1975, en una decisión inédita el gobierno cubano, unos 20 militantes del Partido Socialista fueron admitidos en las academias de las Fuerzas Armadas Revolucionarias (FAR) de Cuba para iniciar una carrera como oficiales regulares"21. El escenario, propio de la guerra fría, contribuyó como el espacio idóneo para la colaboración entre las naciones de la órbita soviética en la instrucción especializada de combatientes internacionalistas. Como comenta Cristián Pérez, las redes de alianzas se movieron en múltiples países que acompañaron en la estructuración de una amplia red de preparación militar. El autor menciona,

Esta formación fue complementada con cursos militares en Bulgaria, hasta donde se trasladan algunos campesinos que antes del golpe fueron enviados por la Confederación Campesina e Indígena 'Ranquíl' a realizar cursos de tractoristas en la Unión Soviética. Es probable que en otros países como la RDA y Rumania también se hayan formado militares comunistas chilenos ${ }^{22}$.

Jóvenes comunistas, exiliados socialistas, militantes miristas y miembros del MAPU, fueron los que acogieron el ofrecimiento, vieron la oportunidad de formarse militarmente en otros países, en escuelas de guerrilla urbana y rural, con el convencimiento de poder ganar experiencia para retornar a Chile y derrotar a la dictadura, o en su defecto contribuir en tierras foráneas en la lucha por la democracia y la construcción del socialismo. Por ejemplo, un grupo de combatientes del MAPU, deciden integrarse a la guerrilla salvadoreña y crear el Contingente Internacionalista Darío Hernández. Entre ellos; Ramiro, Memo, Juan, Horacio y Sergio Mancilla Caro. La compilación de Sergio Reyes sobre el destino de Mancilla Caro, nos permite revivir los últimos pasos del joven mapucista.

En Panamá, Mancilla, apoyó, las tareas que desarrollaba por ese entonces, el FSLN. Colabora con la guerrilla nicaragüense en las tareas de apoyo económico. A comienzos de los años 80', Mancilla se vincula con el

\footnotetext{
${ }^{20}$ Rolando Álvarez. Op Cit. Hay que mencionar que el vínculo estratégico entre jóvenes chilenos que partieron a formarse a Cuba, inicialmente como médicos, se inicio en pleno proceso de la UP. Fueron en gran medida estos, cerca de 200 al momento del golpe militar, los que más tarde comenzaron su preparación militar en las academias de guerra caribeña.

${ }^{21}$ Pascale Bonnefoy. Op Cit.

${ }^{22}$ Cristián Pérez. Op Cit, pp: 149.
} 
MAPU Garretón. Con esta organización habían acordado, en 1981, ingresar a El Salvador, FMLN. Esta decisión tenía que ver con mejorar la preparación militar e ingresar a combatir a Chile a la dictadura. En Octubre de 1981, Mancilla Caro, cayó acribillado por las balas de soldados del ejército salvadoreño ${ }^{23}$.

El devenir del ciclo guerrillero estaba en su cenit cuando un grupo de comunistas chilenos, deciden integrarse a la lucha colombiana. Colaboraron como instructores en escuelas para campesinos, mayoritariamente en las FARC y en menor medida en el ELN. Uno de ellos, era Moisés, quien relata, "Me acuerdo que estaba muy emocionado, como que me costaba creer que estaba con la leyenda de la guerrilla colombiana sentada en la misma mesa. Marulanda me sorprendió mucho, lo encontré un tipo muy práctico, muy inteligente pero incapaz de perder la sencillez y la generosidad"24. Entre estos combatientes, se encontraba Elcio Reyes, quien caería muerto luego de la explosión de una bomba en un operativo guerrillero en julio de 1994.

El amplio curso de estas prácticas, nos lleva a diversificar y complejizar aún más las experiencias internacionalistas ${ }^{25}$. Lo que nos convoca ahora, es conocer el relato de otros internacionalismos, cobijados en el ideal de colaboración de clase, que se unieron bajo un panorama adverso de enfrentamiento, en contra de un enemigo planetario. Queremos, además, como hemos planteado, cruzar ciertos conceptos claves para contribuir, desde un primer acercamiento, en la edificación de una red teórica que entrecruce las experiencias internacionalistas, para así moldear de mejor forma el internacionalismo como concepto histórico.

Es importante recalcar antes de comenzar a conocer estas historias, que si bien son experiencias únicas e individuales, que no actuaron en forma coordinada, no se conocieron entre sí, las piezas teóricas que van elaborando se entrecruzan como partes de un mismo rompecabezas. Es interesante poder observar la similitud de estas memorias militantes y reafirmar su pertenencia como sujetos políticos de un contexto específico. Como señala Elizabeth Jelin,

...la "experiencia", es vivida subjetivamente y es culturalmente compartida y compartible. Es la agencia humana la que activa el pasado, corporeizado en los contenidos culturales (discursos en un sentido amplio). La memoria, entonces, se produce en tanto hay sujetos que comparten una cultura, en tanto hay agentes sociales que intentan "materializar" estos sentidos del

\footnotetext{
${ }^{23}$ Sergio Reyes, Compilador. "La Historia de Sergio Mancilla Caro, un Guerrillero Internacionalista Austral" edición digital, 2014, pp: 71.

${ }^{24}$ Testimonio de Moisés, ex guerrillero chileno preparado en Cuba que estuvo en Nicaragua y más tarde en Colombia. En, Javiera Olivares Mardones, Op Cit, pp: 211.

${ }^{25}$ Los vínculos de chilenos y chilenas en historias de este tipo, son múltiples y variadas, lo que nos lleva a evidenciar la existencia de un amplio entramado de colaboración Internacionalista. Un ejemplo de lo anterior, puede encontrarse en la investigación de Florencio Domínguez, Las conexiones de ETA en América, Chile, Debate, 2011, quien relata los vínculos del MIR chileno, el M19 colombiano y ETA.
} 
pasado en diversos productos culturales que son concebidos como, o que se convierten en, vehículos de la memoria, tales como libros, museos, monumentos, películas o libros de historia ${ }^{26}$.

\section{Bajo la herencia del Che, la historia de Fermín}

Fermín creció en un sector popular de Santiago de Chile a principios de la década del cincuenta. Su padre fue un obrero metalúrgico que derivó hacia la actividad comercial en las humildes ferias libres de la capital. Fermín había nacido en 1947, y su futuro estaría cruzado por la convicción de que era posible la construcción de una sociedad mejor.

En los años sesenta comenzó a despertar su interés por las grandes transformaciones sociales del período. Fermín recuerda, "Me interesaba lo que ocurría en África, en todo eso de la descolonización del continente...Como vivíamos cerca de la sede de la Universidad, empecé a observar y después a vincularme con las protestas universitarias...yo ya me sentía parte de un sector social que necesitaba expresarse en la calle"27.

Para fines de los sesenta, el país se enfrentaba una nueva disputa electoral, donde la figura de Salvador Allende aparecía liderando los proyectos de transformación social. La participación activa en política era un dilema vital. Este es el contexto en que Fermín empieza formalmente a vincularse con la política. "Me integro al MIR en medio de la discusión si se apoyaba a Allende o no"28.

Con la UP en el poder, Fermín toma contacto con militantes extranjeros que salieron de sus países de origen, buscando nuevos horizontes revolucionarios o encontrando asilo contra la opresión. "En Pudahuel, Barrancas, se vivió una experiencia de toma de terrenos, se instaló un CERA, (Centro de Reforma Agraria), a esta experiencia de autogestión poblacional campesina, llegaron militantes Tupamaros, del MIR peruano, del ERP argentino, de diferentes países."

El vínculo con el ELN boliviano surgió rápidamente ${ }^{29}$. La mayoría de sus principales dirigentes estaban en Chile luego del fracaso del foco de Teoponte, a fines de

\footnotetext{
${ }^{26}$ Elizabeth Jelin. Op Cit, pp: 37.

${ }^{27}$ Fermín, entrevista con el autor. Santiago de Chile, 16 de enero de 2015.

${ }^{28}$ Sobre el MIR, ver entre otros; Eugenia Palieraki, ;La revolución ya viene! El MIR chileno en los años sesenta, Santiago, LOM, 2014. Igor Goicovic. Trabajadores al poder. El Movimiento de Izquierda Revolucionaria (MIR) y el proyecto revolucionario en Chile 1965-1994, Concepción, Ediciones Escaparate, 2016.

${ }^{29}$ El Ejército de Liberación Nacional, fue la organización que estructuró Ernesto Che Guevara en el proyecto guerrillero boliviano. Luego del fracaso del foco de Nancahuazú, la organización vuelve a retomar la lucha armada, volcándose a la estructuración de un segundo foco guerrillero, esta vez en la zona de Teoponte. Esta última fase comenzó a operar a mediados de 1970, y esta vez, con la participación directa de chilenos en la montaña, entre otros combatientes. En noviembre del mismo año, la continuación de la guerrilla guevarista estaba aniquilada. El gobierno de Salvador Allende, funcionó como espacio de protección y asilamiento para los sobrevivientes, entre los que se contaban al jefe de la guerrilla, Chato Peredo. Para más detalle ver; Gustavo Rodríguez Ostria. Sin tiempo para las palabras. Teoponte. La otra guerrilla guevarista en Bolivia. Bolivia, Kipus, 2006.
} 
1970. La persecución política y los acuerdos de amnistía, posibilitaron la salida hacia territorio chileno de muchos miembros del ELN. Desde acá también se comenzó a replantear la creación de un nuevo proyecto revolucionario. "Acá estaba el Chato, Nila Heredia...gran parte del ELN boliviano estaba acá en Chile”.

Fermín junto a otros compañeros, deciden a mediados de 1971 viajar a Bolivia e ingresar al ELN. El suelo que vio caer al Che, seguiría siendo una tierra en donde se visualizaba el eslabón más débil del imperialismo capitalista, así junto a Fermín, Arnaldo Meyer, Ramón Molinet, Julio Ulloa, Agustín Carrillo y Guillermo Véliz, entre otros, formaron parte del grupo de chilenos que se unieron al esfuerzo por revitalizar el proyecto guevarista boliviano. Esto implicaba ratificar la concepción de que el proceso revolucionario era uno sólo, y que lo que estaba ocurriendo en Chile, podía ser replicado en suelo boliviano. "Entre quedarse acá y partir a Bolivia, que era una concepción latinoamericanista concreta, optamos por esa posibilidad de ir a Bolivia".

La militancia que comenzaba a reorganizarse debió enfrentar la represión cruenta y avasalladora del nuevo régimen del general Hugo Banzer. El panorama del ELN lo resume de manera concluyente el Historiador boliviano Gustavo Rodríguez Ostria.

...el 12 de mayo la policía política abatió en un barrio periurbano de La Paz a Ertl (Mónica)y Ukaski (Osvaldo). El ELN quedó sin dirección y prácticamente sin cuadros en Bolivia. Pese a la debacle, el plan, que consistía en reagrupar fuerzas en Chile y de allí desplazarse hacia Bolivia, estableciendo un foco en un lugar selvático, hasta ahora desconocido, perduró ${ }^{30}$.

Guillermo Véliz, Gastón, quien fuera uno de los chilenos sobrevivientes de la guerrilla de Teoponte, encontró la muerte en su anhelo de retorno guerrillero, a manos de la represión boliviana en mayo de 1972. Agustín Carrillo, Negro, fue capturado en julio del mismo año en Oruro. Torturado y ejecutado, sus restos mortales fueron repatriados recién en el año 2008. El destino de Fermín corrió por otros canales. "El año 76' caímos presos en Bolivia. Los bolivianos, el ejército, tenían apoyo brasileño, ya estaba en marcha el Plan Cóndor. Estuve 6 meses preso hasta que la policía boliviana nos entrega por Arica a la policía chilena".

Luego de seis meses en la cárcel, y en plena dictadura, Fermín se reintegra al MIR, insertándose en las poblaciones de Santiago, reclutando y acogiendo a compañeros perseguidos por temas de Derechos Humanos. Esta labor la desempeñó hasta que, en 1980, es detenido nuevamente. Su reclusión duró hasta 1991, un año después del fin de la dictadura militar de Pinochet.

\footnotetext{
${ }^{30}$ Gustavo Rodríguez Ostria, "De la guerra de guerrillas al partido de cuadros: del ELN al PRT-B en Bolivia,
} 1967-1979. En Pablo Pozzi, Op Cit. pp: 76. 


\section{Encumbrándose por los andes peruanos, la historia de Rubén}

Rubén nació en 1959 en Viña del Mar, año del triunfo de la Revolución Cubana. Era un adolescente cuando se produjo el golpe militar. Su formación familiar, el contexto poblacional y político, lo acercaron a la militancia cuando las distintas organizaciones empezaban a reagruparse luego del 11 de septiembre. Ingresó al MAPU con cortos 17 años y se integró a trabajar en la Comisión de Derechos Humanos Juveniles. Rubén recuerda, "Para mí el MAPU, tenía un discurso muy autocrítico del rol de la UP, y un análisis visionario de la dictadura de Pinochet. El año 76 yo entro a militar al MAPU, con la intención de recomponer lo que había sido el golpe" 31 .

A fines de los años setenta, un grupo de dirigentes del MAPU, viaja a Europa a nutrirse de las nuevas corrientes de la izquierda, buscar apoyo para la resistencia en contra de la dictadura. Otro grupo menor se traslada hacia Centroamérica a tomar contacto con las guerrillas nicaragüense y salvadoreña. "En Chile, nos quedamos un grupo continuando la labor de resistencia a la dictadura, junto con el MIR, radicales, DC chascones". El viaje de la mayoría de las direcciones nacionales hacia el viejo continente trajo como resultado un viraje político de la visión del partido, un acercamiento hacia la socialdemocracia europea. "Producto de la conversión del MAPU en Europa, pasamos a formar el MAPU-Lautaro, con la idea de buscar el tronco histórico". La creación de esta orgánica, tenía como foco, la rearticulación del movimiento social y en especial, el trabajo hacia el sector juvenil, la nueva generación de jóvenes pobladores que a la sombra del nuevo Chile formaban parte de los postergados que pateaban piedras en las poblaciones. A juicio de la historiadora, Cristina Moyano, la organización condensaba la expresión de un sentir identitario en formación. La autora comenta, "La imagen de una sociedad en rebeldía nutrió los sueños de muchos militantes del MAPU, que sintieron que este reventón social, que escapo al control de los partidos, era la mejor expresión de que este discurso, más que un anhelo, era una realidad" 32 . Había que reimprimirle, como señala Rubén, el sello revolucionario al partido.

Corría el año 1982 y el trabajo de Rubén y sus compañeros en la CODEJU se hace cada vez más intenso y complejo. El nacimiento de las masivas protestas en contra del régimen comienza a tomar mayor peso. Este es el escenario en el cual Rubén, junto con un grupo de militantes, son detenidos por la represión. "Caigo en un operativo de recuperación de dinero, yo hacía labores de logística...Estoy detenido unos meses y gracias a la labor de abogados de DDHH, me sacan de la cárcel...luego de salir de la cárcel, el partido me saca al extranjero, a formar parte del Frente Externo del MAPU-Lautaro."

\footnotetext{
${ }^{31}$ Rubén, entrevista con el autor. Viña del Mar, 14 de octubre de 2015.

32 Cristina Moyano Barahona, El MAPU durante la dictadura. Saberes y prácticas políticas para una microhistoria de la renovación socialista en Chile, 1973-1989. Santiago, Ediciones Universidad Alberto Hurtado, 2010, pp: 393. El Movimiento de Acción Popular Unitaria, MAPU, había nacido en 1969, luego de un clima de ascendente radicalización, cuando un grupo de militantes jóvenes de la Democracia Cristiana decide apartarse de la organización. Su accionar estuvo caracterizado por la radicalización del discurso y el trabajo hacia sectores campesinos. A fines de 1982 deciden crear el Movimiento Juvenil Lautaro, como parte de una estrategia para luchar contra la dictadura.
} 
El periplo de Rubén, lo llevó a recalar primeramente en Perú. “El año 83’ salgo clandestinamente hacia el Perú... salgo con tres destinos. Después de Perú yo iba a Bolivia, me tenía que trasladar a El Salvador, Nicaragua... nosotros ya teníamos gente en El Salvador, en el Frente Farabundo Martí".

La ubicación estratégica del país y las relaciones preexistentes entre el MAPU y la lucha armada peruana, posibilitó el enlace de Rubén con el MRTA ${ }^{33}$. En primera instancia, Rubén trabajó en la creación de una red de apoyo para los "emerretistas", estableciendo vínculos con otras orgánicas. Y una segunda tarea, debía colaborar en el abastecimiento para la implementación de la lucha armada en Perú. Como señala Peter Klarén, la manifestación de la violencia política en el Perú, responde al fracaso político de las elites económicas y políticas, en conformar en el largo tiempo, una nación que permita la inclusión de los vastos sectores postergados, que no se sienten representados en el proyecto de construcción social ${ }^{34}$. El rebrote de las acciones armadas, tanto de Sendero Luminoso como del MRTA a partir de comienzos de los años 80', aún cuando el país se encontraba en la fase de reconstrucción política, este nuevo escenario era una falsa lectura de avance democrático. Es en ese contexto en el cual Rubén, recala en Perú. "Yo me vinculo con el MRTA porque teníamos relaciones internacionales con el MIR peruano, con el MIR boliviano, VR peruana...yo era joven y me encuentro con el MRTA que hace un reconocimiento a una figura emblemática y rebelde".

Los emerretistas, plantearon un trabajo estratégico que contemplaba dos etapas. La primera incluía; el reclutamiento clandestino de militantes, la necesidad de recopilar sumas de dinero y armamento, y la realización de escuelas de homogenización político-militar. En una segunda fase, se planificó la iniciación de una propaganda armada, que tenía como principal motor la aparición pública de la organización a través de acciones guerrilleras en el país. "Yo me establezco en Perú, pero mi tarea implicaba viajar y tomar contacto con otras organizaciones, sobre todo con Centroamérica, desde allá viajaba el armamento, desde Panamá, que era un punto estratégico muy importante".

Tras tres años trabajando con el MRTA, Rubén comienza a vislumbrar la posibilidad de retornar a Chile y unirse a la cada vez más fuerte oposición a Pinochet. Para Rubén, el MAPU-Lautaro se planteaba la necesidad no sólo de derrocar a la dictadura, sino que, de construir un nuevo modelo social, a partir de la recuperación de una mirada latinoamericana más integradora. Asumiendo los riesgos del retorno, Rubén recala a

\footnotetext{
${ }^{33}$ El Movimiento Revolucionario Tupac Amaru, MRTA, fue una organización armada del Perú de inspiración guevarista, que nació luego de la confluencia entre el PSR ML y el MIR EM, que desde 1980 venían trabajando conjuntamente frente a la visualización de una nueva situación prerrevolucionaria, asumida ésta luego del triunfo sandinista en Nicaragua, de la ofensiva del Frente Farabundo Martí en El Salvador y el auge de la lucha armada en Colombia, entre otros. En 1982, se crea el MRTA con el inicio de algunas acciones armadas y el desarrollo de escuelas guerrilleras. Para dicho fenómeno ver; Centro de Estudios y Promoción del Desarrollo, Violencia Política en el Perú, 1980-1988. Perú, edición digital, 1989. Nelson Manrique, El tiempo del miedo: la violencia política en el Perú, 1980-1996. Lima, Fondo Editorial del Congreso del Perú, 2002.

34 Peter F. Klarén. ““El tiempo del miedo’ (1980-2000), la violencia moderna y la larga duración en la historia peruana”, en Anne Pérotin-Dumon (dir.) Historizar el pasado vivo en América Latina. Edición digital.
} 
mediados de 1986 en nuestro territorio. Su organización había experimentado cambios significativos que tenían directa relación con el contexto vivido; el ocaso del régimen de Pinochet, el fin del socialismo real, y el giro de las dinámicas de protesta social. "A fines de los años ochenta, el MAPU-Lautaro comenzó a crecer exponencialmente sin el necesario trabajo político, sin la filosofía política y eso era tremendamente maleable". Como señala, Cristina Moyano, el Lautaro, y su accionar rebelde, fue incomprendido y desfasado en tiempo y forma. Fue criticado por la antigua generación de políticos que ya empezaba a pactar la transición, el Lautaro quedó descolgado de la historia y dogmatizado como jóvenes subversivos offsider ${ }^{35}$. Más allá de la autocritica política de Rubén y los suyos, la organización que habían pensado, chocó con los ideales del nuevo Chile que comenzaba a edificarse.

\section{De Argentina a Canadá, pasando por Nicaragua. La historia de Daniel, Ricardo Antonio}

Daniel, de nombre político Ricardo Antonio, nació en una modesta familia de Viña del Mar, en 1956. Hijo de un obrero municipal, pudo estudiar en el liceo y conectarse con la álgida discusión política de comienzos de los años 70'. Es en este espacio en donde organiza junto con otros compañeros, el MOPE, Movimiento de Obreros, Pobladores y Estudiantes. Daniel recuerda, "Era una organización precaria, muy rudimentaria, pero tenía la relación política entre los que éramos estudiantes y veníamos de las poblaciones de Viña"36.

El año 1972 ingresa a la Universidad de Chile, a lo que se conocía como el pedagógico. En medio de un ambiente de enriquecedora discusión política, y en un espacio de creciente desarrollo de la militancia universitaria como lo fue la Universidad de Chile en Valparaíso, Daniel conoce al MIR. Luego del tanquetazo, en junio de 1973, se organiza en la universidad una reunión dirigida por uno de sus máximos dirigentes, Bautista Van Schouwen. "Imagínate, llegó a hablar al pedagógico el Bautista, y nos habla de una organización más estructurada, con un discurso claro y que nos hacía sentido...ahí yo comienzo a militar en el MIR, dos meses antes del golpe”. Daniel ingresa al MIR, y comienza a tomar vida, el camino político de Ricardo Antonio.

La fase represiva de la dictadura (ciclo 1973-1978) que termina con la disolución de la DINA un año antes, el giro político en los EEUU hacia las dictaduras militares latinoamericanas, y las diferencias al interior de la junta militar, permitieron el renacimiento sigiloso de una nueva generación de militantes, que se articularon con aquellos experimentados cuadros que lograron sobrevivir al exterminio pos 1973. Estos, lograron reorganizar una nueva fase de rebelión en contra de la represión estatal. Como plantean Julio Pinto y Sebastián Leiva, en relación al MIR, "Entre 1979 y 1981 el partido se

\footnotetext{
${ }^{35}$ Cristina Moyano Barahona, Op cit.

${ }^{36}$ Daniel, Ricardo Antonio, entrevista con el autor. Viña del Mar, 10 de marzo de 2017.
} 
cohesionó y articuló sus esfuerzos tras una táctica que tuvo una clara centralidad estratégica. Se logró tomar y mantener la iniciativa táctica con un reducido nivel de bajas en la fuerza combativa. Se contabilizan 158 acciones entre 1980 y 1981 "37. Cobraron fuerza los núcleos de base de las poblaciones empobrecidas, y fue en este espacio en que Ricardo Antonio, ya clandestino, logró colaborar en la reagrupación y coordinación de los pobladores. Esto no estuvo exento de riesgos y dificultades. Ricardo Antonio relata, "Nosotros vivíamos en la población Francisco Vergara, y la situación era complicada...una noche de balacera, cayó un compañero muerto en la puerta de mi casa, yo tenía un hijo recién nacido, ahí decidimos salir de Chile".

En 1985, y sin ningún resguardo ni contacto político, Ricardo Antonio llega a Buenos Aires. "Al comienzo dormíamos en la calle, la gente fue muy solidaria con nosotros... al poco tiempo, la gente del MIR en Argentina, el compañero Ibsen, que era el encargado en Argentina, toma contacto con nosotros y yo me vinculo nuevamente con la organización". Si bien la dictadura argentina ya había concluido, y el presidente Raúl Alfonsín iniciaba el proceso de democratización en la sociedad trasandina, los aparatos represivos de la dictadura chilena seguían operando en suelo argentino, entre otras tareas, en la infiltración de los refugiados políticos que se congregaban en Casa Chile, centro de reuniones de miristas, mapucistas, socialistas y comunistas.

Buenos Aires representó no sólo un espacio de refugio y rearticulación familiar, sino que además se transformó, al igual que los otros internacionalistas, en un lugar de trabajo político. "Los comunistas estaban trabajando en el plan retorno, en el operativo de derrotar a la Dictadura, en el atentado a Pinochet, la internación de armas y todo eso".

Aunque un número importante de las fuerzas de oposición en Chile estaban encaminando el proceso de transición pactada con el régimen militar, la convicción de Ricardo Antonio, y de los que trabajaban con él, apuntaban hacia otra dirección. Ricardo Antonio comenta,

En Argentina hubo mucha solidaridad con Chile. Organizamos muchas actividades a favor de la resistencia, trabajamos con los pobladores en conventillos de Buenos Aires, realizábamos escuelas de formación política con el ERP y con Partido Obrero, trotskista, en realidad eran escuelas de formación militar. Te cuento que la gente del ERP tenía una librería en calle Montevideo con Corrientes, en pleno centro, era una fachada de un lugar de reuniones. Con ellos salíamos a la provincia a practicar tiro y esas cosas.

\footnotetext{
${ }^{37}$ Julio Pinto Vallejos, Sebastián Leiva Flores, "Punto de quiebre: el MIR en los ochenta", en, Varios autores Su revolución contra nuestra revolución. La pugna marxista-gremialista en los ochenta, Santiago, LOM, 2008, pp: 94.
} 
Estos movimientos alertaron a los aparatos de seguridad de la Junta Militar que estaban cautos frente a los lazos de la militancia chilena en el extranjero, sobre todo luego del fallido atentado a Pinochet en el Melocotón en septiembre de 1986. "En una ocasión nos detuvieron un grupo de civiles, nos amedrentaron, nos amenazaron con armas, nosotros supimos por la forma de hablar que eran chilenos, creo que era la CNI que todavía estaba operando en Argentina". Este escenario poco auspicioso, se entroncó con la crisis y posterior división del MIR. Los balances de la lucha contra la dictadura, los objetivos próximos a seguir, tomando en cuenta el viraje del contexto político interno y las alianzas con otras organizaciones políticas, evidenciaron las diferencias dirigenciales. A comienzos de 1987, un sector se agrupa con Nelson Gutiérrez y otros siguen a Andrés Pascal Allende y Hernán Aguiló. Meses más tarde, este último concentraría una nueva división de la colectividad, reconociéndose tres grupos miristas.

La inseguridad volvió a hacerse patente en la mente de Ricardo Antonio. La Agencia de Naciones Unidas para Refugiados, ACNUR, tomó contacto con él y le ofreció salir hacia Canadá. Eran los meses anteriores a la celebración del plebiscito de octubre de 1988. Ya en Montreal, junto con un grupo de exiliados chilenos crean el Buró de Prisioneros Políticos, organización que en la práctica era el MIR en Canadá. "Me contacta el Cata, que era el encargado del MIR allá, y ahí yo me reorganizo con la militancia. Desde allá, continuamos con las tareas en pos de coordinar, lo que para entonces eran, las últimas acciones de la resistencia en Chile".

En la convicción de Ricardo Antonio, todavía está presente la idea de la lucha en contra de la Dictadura, por lo que, las lógicas del pacto político con el régimen militar, estaban fuera de toda comprensión. Por ese entonces, Cuba todavía seguía preparando a unos pocos militantes chilenos en las bases de formación militar ${ }^{38}$. Ricardo Antonio, realiza un viaje de 6 meses a la isla caribeña a recibir instrucción. "Estuvimos en Cuba en cursos de formación política, pero que en realidad eran de manejo armamento. También estuvimos en Nicaragua, en Estelí, para colaborar y conocer el avance del proceso sandinista".

Ya con el retorno de la democracia chilena, Ricardo Antonio decide regresar a su país natal. Las posibilidades de retomar su antiguo trabajo como pedagogo, y volver a vivir en la ciudad que lo vio partir, jugaron a favor para reclamar su retorno en 1992.

\section{La lucha Sandinista, la historia de Patricio}

Patricio es un antiguo militante revolucionario. Nació en Santiago en 1936 y desde joven acompañó a su padre en el trabajo, desempeñándose como alarife en tareas de la construcción. Su interés en la militancia se acrecentó en la universidad desde donde integró la Federación Juvenil Socialista, y más tarde, en el año 1961, la Brigada Universitaria Socialista, la BUS. A mediados de los años sesenta participa en la fundación del MIR

\footnotetext{
${ }^{38}$ Para más detalles sobre estas fases de preparación, ver, Javiera Olivares Mardones, Op Cit, y Pascale Bonnefoy, Op Cit.
} 
chileno, bajo la lógica de conseguir la reagrupación de las distintas tradiciones revolucionarias existentes.

Luego de cuatro años de militancia, vino el quiebre interno. El año 1969 un importante número de miristas son separados de la organización. "Yo había quedado como muchos de nosotros muy ofendido en lo íntimo por esta maniobra de la mayoría del comité central (MIR)...nos pasaban la aplanadora. La mayoría del comité central quería un aparato armado...yo en lo personal quedé bastante molesto"39. Ya fuera del MIR, Patricio retoma sus vínculos con el PS chileno ${ }^{40}$. "Cuando volví de estar relegado, el año 1970, me vinculé con el Regional Cordillera del PS...había un pequeño grupo de gente afín que había pasado por grupos trotskistas dentro de ese regional".

Una vez producido el golpe militar de septiembre de 1973, buscó asilo, primeramente, en la embajada de Italia y luego en la de Honduras. Luego de unos meses en esta dependencia diplomática, y de angustiosas indecisiones por parte de las autoridades centroamericanas, un grupo de refugiados logran salir de la embajada rumbo a Honduras.

La aventura en suelo hondureño no fue fácil. "Nos encontramos con que el gobierno hondureño no había autorizado nuestro asilo, y más bien había sido una gestión del embajador en Chile. No nos querían en Honduras". A fines de 1974, finalmente son expulsados hacia Costa Rica. En estas tierras de cobijo, Patricio comienza a tomar nuevos rumbos revolucionarios. "Los sandinistas tenían base permanente en Costa Rica que les permitía conspirar, y entrar y salir... y con esa base nosotros nos relacionamos muy tempranamente. Nosotros constituimos el PS en Costa Rica con 73 militantes" ${ }^{4}$.

La fuerte ofensiva sandinista a partir de 1977, estimuló a los socialistas chilenos en Costa Rica, para conformar la Brigada Salvador Allende, BRISA. Aquel país, presentaba condiciones idóneas para la articulación de una fuerte opción somocista. Como señala Fernando Mires,

\footnotetext{
${ }^{39}$ Patricio, entrevista con el autor. Casablanca 11 de junio de 2016.

${ }^{40}$ El Partido Socialista Chileno, es una organización fundada en 1933 por distintas orgánicas de izquierda, nucleadas en torno a su oposición al comunismo pro soviético e influenciadas por corrientes nacionalistas de izquierda. Al poco tiempo de su fundación, comenzó a construirse como la segunda fuerza más importante de la izquierda después del PC chileno, y con una fuerte presencia en sectores medios profesionales, intelectuales y estudiantiles. Siempre en sus filas convivieron distintas tradiciones izquierdistas, encontrándose casi permanentemente un sector cercano al trotskismo. Existe una amplia bibliografía sobre el PS. Ver entre otros; Luis Corvalán Márquez. "Surgimiento de nuevas identidades en la historia política reciente. El caso del partido socialista de Chile", Revista Mapocho No 38, Santiago, Dibam, segundo semestre 1995. Juan Carlos Gómez Leyton. "La rebeldía socialista. El PS en la década de los sesenta 1959-1970". Documentos de Trabajo, Santiago, FLACSO, Nº 82, marzo 1993.

${ }^{41}$ El Frente Sandinista de Liberación Nacional, FSLN, fue una agrupación originada a comienzos de la década del 60', y que aglutinó a diversas corrientes opositoras al gobierno de Anastasio Somoza. Los sandinistas supieron definir una política mancomunada de rebelión en contra del régimen y acrecentar la lucha en las ciudades y mantener zonas rurales bajo su control. Para 1978, comienza una ofensiva generalizada contra el somocismo, lo que decantó en el triunfo sandinista de julio de 1979.
} 
Costa Rica, por ejemplo, temía que en caso de seguir Somoza en el gobierno se produjera una regionalización del conflicto. Ya de hecho ese país tenía que recibir oleadas de refugiados nicaragüenses huyendo de los bombardeas de Somoza. Además, los sandinistas tenían buenas relaciones con el partido de oposición en Costa Rica, el Partido de Liberación Nacional, del cual Edén Pastora, comandante sandinista, era militante ${ }^{42}$.

Este escenario era el propicio para que los anhelos de Patricio de continuar con la lucha por la democracia y la dignidad, se hicieran reales.

La BRISA tomó contacto con la Brigada Internacionalista Simón Bolívar, formada en Colombia en mayo de 1979 por iniciativa de la Fracción Bolchevique de la Cuarta Internacional, en donde participaba el trotskista argentino Nahuel Moreno. El llamado a colaborar con los sandinistas fue amplio y diverso, integrándose militantes argentinos, colombianos, brasileños, haitianos, chilenos, costarricenses, salvadoreños y mexicanos, entre otros, quienes se sumaron en las distintas fases y lugares del conflicto.

Una vez producido el triunfo del FSLN, en julio de 1979, Patricio vuelve a Costa Rica a seguir desde allí colaborando con la resistencia chilena. "El trabajo de estos núcleos socialistas, filiales en el exilio, era apoyar la resistencia en Chile...lo que hacíamos, fundamentalmente, era hacer negocios para juntar plata para mandar para acá (Chile). Tuvimos un cafetal, y como cuatro o cinco empresas más”.

Si bien Patricio mantenía un trabajo estable como docente en la universidad en Costa Rica, en 1982 decide trasladarse hacia México, y buscar nuevas alternativas no sólo laborales, sino que también políticas. "Hubo muchas cosas extrañas e indeseables con toda la ayuda que mandamos para Chile, creo que se construyó también un mito sobre la resistencia en Chile...fue ahí que me cabrié y me fui a México. Tomamos contacto con los restos de la guerrilla de Genaro Vásquez, en el Estado de Guerrero”. Fue hasta 1990 que Patricio residió en México y como el resto de los militantes internacionalistas que protagonizan nuestro relato, decidió volver a Chile para reiniciar su vida y sus nuevos proyectos políticos.

\section{Las nociones internacionalistas}

En los testimonios recogidos, hay una espina dorsal que recorre la experiencia y que aflora en la memoria de los militantes. Esta lógica aparece como una necesidad frente al contexto vivido, a la visión estructural de la sociedad y la latencia del sacrificio. Es la militancia internacionalista la que edifica el discurso político y forma de operar. Según Patricio; "Para la gente con formación trotskista, para mí es una formación marxista

\footnotetext{
${ }^{42}$ Fernando Mires, La rebelión permanente. Las revoluciones sociales en América Latina. México, Siglo XXI editores, 2001, pp: 427.
} 
leninista nada más, los conceptos están plenamente claros... primero el proletario no tiene patria, es internacionalista. En segundo lugar, la clase, como decían los viejos...la clase es internacionalista prácticamente por definición". En un mismo plano, Fermín apunta; "El latinoamericanismo se relaciona con el internacionalismo...el sentido de clase, el sentimiento de clase es algo que se da a nivel mundial". Rubén nos comenta desde un plano más vivencial y menos doctrinario; "Se tiende a pensar que el internacionalismo son aquellos hombres que van a pelear guerras ajenas...la concepción internacionalista es tal cual como se dice, tú no tienes bandera ni territorio... yo llegue devuelta a Chile y fui muy maltratado porque yo llegue pensando como boliviano, peruano, argentino...". Para Ricardo Antonio la lógica internacionalista se vincula nuevamente con el concepto de clase, él lo plantea así; "Como hijo de un obrero municipal hablo desde la pobreza, de cómo la oligarquía te pone la pata, ese concepto es universal (Internacionalismo)...cuando estuve en el extranjero siempre busqué a los de mi clase...los de la clase alta, la oligarquía afuera, son los mismos. Los explotados, los pobres somos todos en todas partes".

Desde esta mirada, la patria, la nación, son conceptos reelaborados y trastocados del sentido formal. Fermín comenta;

La patria no es igual que para un habitante que vive en una zona modesta, versus a uno que vive en el sector alto, los militares no defienden a todos por igual... el Estado de cualquier parte defiende los intereses de clase... entonces el concepto de patria es una cosa bastante secundaria respecto del sentimiento de clase, para mi es más importante el sentimiento de clase, que de patria y eso lo he vivido en el sentido de la experiencia... a nivel mundial debemos defendernos.

Para Rubén, las lógicas son similares;

Por el cargo que yo ocupaba en el Frente Externo, tuve la posibilidad de moverme mucho, de contactarme con distintas orgánicas revolucionarias, de conversar con mucha gente, un proceso rápido de aprendizaje, muy enriquecedor, muy vertiginoso que te conflictúa mucho, pone en juego una serie de cosas, yo me di cuenta de que perdí la identidad, perdí el concepto de chilenidad... y ahí me quedo apátrida.

En consonancia, Patricio describe; "Las fronteras, las aduanas y toda esa mierda son cuotas de las castas del dinero, del modo de vivir burgués... eso no tiene mayor discusión”. Ricardo Antonio emula los principios bolivarianos. Él se refiere en los siguientes términos; "No hay una nación, esta la patria grande, nosotros le decíamos así, esa es nuestra patria, América".

La convivencia diaria en suelos hostiles y contextos vitales, hacen moldear la idea de un compañerismo fuera de lo cotidiano. Ricardo Antonio recuerda sus vivencias en este plano; 
En Argentina nos encontramos con uruguayos, bolivianos, brasileños, la generosidad fue muy grande. En una ocasión trabajando en la construcción, a unos compañeros bolivianos les pidieron que hicieran algo que no les correspondía, y todos nosotros, los que éramos militantes, le dijimos; no hermano no te metas en eso. Eran nuestros hermanos, nuestros compañeros.

Fermín lo vivió de esta forma; "Hay hermandad de clase, los compañeros con los que trabajábamos eran campesinos, y por ende, se sentía la cercanía social, más allá del origen nacional...me tocó compartir con militantes de origen muy humilde, uno me dijo un día, mira hermanito tu me enseñas a leer y yo te enseño a andar en la montaña". Una vivencia similar es la recogida por Rubén, "Entre los compañeros existe una reciprocidad impresionante, nos reconocimos entre nuestros compañeros, nuestros hermanos”. Para Patricio, la experiencia fue igual de enriquecedora,

No hay diferencias entre militantes extranjeros, ya que uno está hablando en un lenguaje, está hablando en una temática común...en definitiva lo que decía el Che Guevara, el revolucionario tiene que hacer la revolución y punto... entonces las discusiones fueron muy pocas, porque no había mucha discusión frente a la acción concreta que había que hacer que era combatir a la dictadura somocista.

Aún cuando las opciones reales de éxito del proyecto revolucionario pudieran estar en duda, en la memoria de los militantes internacionalistas, el camino de convicción política no permitía (y no permite en el presente para algunos) la posibilidad de otro sendero. Para Ricardo Antonio, la vivencia letal de esos años, permite traspasarle al presente las mismas convicciones, manteniendo vigentes los postulados que movieron a numerosos militantes a vincularse en otras tierras con la rebelión de otros, que era la suya también.

Nunca pensamos que había otra forma, la opción era tomar las armas, tanto en Argentina, Canadá, era la única opción, había en esa época mayor convicción. Teníamos que confiar sólo en los revolucionarios. El único camino es el fierro, la oligarquía, el poder político, no nos van a dar el poder. Con los compañeros argentinos, salíamos a la provincia a probar los fierros, estábamos convencidos de que la lucha armada era el único camino para derrotar a la dictadura.

\section{A modo de cierre}

Tal como señalamos en un comienzo, las historias singulares de internacionalistas chilenos, nos plantean diferentes urgencias disciplinarias. En este sentido, el estudio o el descubrimiento, de estas experiencias militantes, nos enfrenta a la posibilidad de recorrer el 
concepto desde una matriz histórica, antes de hacer referencia a la praxis. Este recorrido, por cierto, es parcial, y todavía puede quedar pendiente una sistematización de estos fenómenos que estén acompañados de un estudio más riguroso con diversas fuentes. Sin embargo, en nuestro primer acercamiento, podernos identificar ciertas exigencias que debiésemos sistematizar, aquellos y aquellas que nos acercamos a estos fenómenos.

La primera consideración tiene relación con la existencia del testimonio directo de una vivencia poco estudiada, y sistematizada, en comparación a lo más conocido y evidenciado, a saber, el internacionalismo chileno comunista en Nicaragua. Estos testimonios dan cuenta de que el fenómeno del internacionalismo, es más amplio, más complejo y requiere de un trato más acucioso. Su diversidad no sólo es un componente de riqueza temática, sino que además nos obliga a plantearnos desafíos en otros campos de estudio de la militancia política. Este ejercicio de rescate lo planteamos también porque creemos necesario colaborar con el fortalecimiento de una historia no oficial que devele los relatos de lucha y que ayude a tensionar los estándares de lo verdadero y lo institucional. Esto es vital, porque como señala Elizabeth Jelin;

...la narrativa nacional tiende a ser la de los vencedores, y habrá otros que, sea en la forma de relatos privados ,de transmisión oral o como prácticas de resistencia frente al poder, ofrecerán narrativas y sentidos diferentes del pasado, amenazador del consenso nacional que se pretende imponer ${ }^{43}$.

En segundo lugar, estas experiencias, se circunscriben a relatos de militancia que se plantearon como mecanismo de obtención del poder, la implementación de la lucha armada y la participación en determinadas orgánicas. Su naturaleza está, en la mayoría de los casos, caracterizada por la ausencia de fuentes escritas, ya sea porque estas fueron destruidas por los aparatos de represión, o las propias organizaciones las hicieron desaparecer como mecanismo de seguridad, o bien no existen porque la edificación identitaria de la orgánica desechó la elaboración teórica de sus postulados, asumiendo la práctica revolucionaria como principal ejercicio. Ahí radica la importancia del relato, del testimonio. Se transforma en la única fuente histórica, lo que plantea otras interrogantes.

Y como tercer elemento, el ejercicio que nos planteamos pretende esbozar una red de conceptos asociados al internacionalismo militante, tarea aún en desarrollo, con el fin de entrelazar las distintas experiencias, y realizar un ejercicio comparativo de estas mismas. Estos conceptos, no fueron construidos necesariamente al alero de una formación teórica militante, sino más bien, fueron tomando forma mediante la vivencia misma. Es interesante hacer notar que en relación al concepto que nutre muestra investigación, el Internacionalismo, está teorizado desde la práctica mayoritariamente, y si bien existe entre los entrevistados un bagaje político de formación marxista, es en esencia en la experiencia vital del límite entre la vida y la muerte, que se fueron configurando sus nociones. En este

\footnotetext{
${ }^{43}$ Elizabeth Jelin. Op Cit, pp: 41.
} 
sentido el Internacionalismo se funde con la idea de un Latinoamericanismo, presente más bien en la cultura del continente, en la leyenda de los próceres de la patria grande, en la identidad de un socialismo americano, en el conocimiento de la geografía humana en contextos de represión y de combate por la dignidad, que en la formación rígida militante de escuelas de preparación partidista.

Nos parece útil poder conectar este fenómeno con los estudios que se han desarrollado en torno al exilio. Como plantean Luis Roniger y Pablo Yankelevich, esta experiencia límite es la que va articulando el nuevo discurso político, las nuevas concepciones militantes que surgen de la praxis misma. De la constancia de la pérdida de derechos, de la ausencia de libertades, de la visibilización de la enajenación del núcleo social de pertenencia. Frente a esto, se abre una nueva posibilidad. Una bisagra política de un nuevo rumbo de identidad militante. Los autores señalan que en el destierro;

...también ocurre que muchos individuos encuentran en el exilio viejas y nuevas formas de identificación con lo latinoamericano, la democracia, la construcción de la sociedad civil y la reivindicación de los derechos humanos; al tiempo que recuperan la posibilidad de manifestar públicamente una lucha por un proyecto nacional, una pertenencia a una nación dispersa y por supuesto el repudio de las prácticas represivas ${ }^{44}$.

Esta nación dispersa es el terreno de la acción política de los militantes que se involucraron en proyectos de transformación social. Fue la lucha, como planteaba Lenin, por la revolución proletaria mundial. Una disputa que no conoció fronteras ni colores nacionales. Aquellas que se involucró en tareas políticas que tenían como destino una solidaridad de clase separada por miles de kilómetros de distancia, geografía que cruza la sierra peruana, la pampa argentina, la selva nicaragüense y el altiplano boliviano.

\section{Bibliografía}

\section{1) Fuentes Impresas}

-Rolando Álvarez. Viviana Bravo. "La memoria de las armas. Para una historia de los combatientes chilenos en Nicaragua", Revista Lucha Armada en la Argentina, $N^{\circ}$ 5, Argentina, 2006.

-Pascale Bonnefoy. Claudio Pérez. Ángel Spotorno. Internacionalistas: chilenos en la Revolución Popular Sandinista. Santiago, Editorial Latinoamericana, 2009.

\footnotetext{
${ }^{44}$ Roniger Luis y Pablo Yankelevich (2009) "Exilio y política en América Latina: nuevos estudios y avances teóricos”. Revista de Estudios Interdisciplinarios de América Latina y el Caribe. Volumen 20, número 1. Instituto Sverdlin de Historia y Cultura de América Latina, Universidad de Tel Aviv pp 10.
} 
- José Miguel Carrera Carmona. Misión internacionalista. De una población chilena, a la Revolución Sandinista. Santiago, Editorial Latinoamericana, 2010.

- Manuel Cortés. Arnaldo Pérez, Yo Patán, memorias de un combatiente, Santiago, Ceibo ediciones, 2015.

-Luis Corvalán Márquez. "Surgimiento de nuevas identidades en la historia política reciente. El caso del partido socialista de Chile", Revista Mapocho No 38, Santiago, Dibam, segundo semestre, 1995.

- Igor Goicovic. Trabajadores al poder. El Movimiento de Izquierda Revolucionaria (MIR) y el proyecto revolucionario en Chile 1965-1994, Concepción, Ediciones Escaparate, 2016.

-Juan Carlos Gómez Leyton. "La rebeldía socialista. El PS en la década de los sesenta 1959-1970". Documentos de Trabajo, FLACSO, Nº 82, Santiago de Chile, marzo 1993.

- Ernesto Che Guevara, "Discurso de Argel, Argelia 24 de febrero de 1965", En la Conferencia Afroasiática en Argelia, México, Editorial Ocean SUR, 2001.

- Eric Hobsbawm. La Era del Capital, 1848-1875, Buenos Aires, Crítica, 1998.

- Elizabeth Jelin. Los trabajos de la Memoria. Madrid, Siglo XXI editores, 2002

-Ernst Mandel, Karl Marx a Proudhon, Sobre la historia del movimiento obrero, Barcelona, Editorial Fontamara, 1978.

-Nelson Manrique. El tiempo del miedo: la violencia política en el Perú, 1980-1996. Lima, Fondo Editorial del Congreso del Perú, 2002.

- Carlos Marx. Federico Engels, Manifiesto Comunista, Santiago, Editorial Universitaria de Chile, 1970.

-Fernando Mires. La rebelión permanente. Las revoluciones sociales en América Latina. México, Siglo XXI editores, 2001.

-Cristina Moyano Barahona. El MAPU durante la dictadura. Saberes y prácticas políticas para una microhistoria de la renovación socialista en Chile, 1973-1989. Santiago, Ediciones Universidad Alberto Hurtado, 2010.

- Javiera Olivares Mardones. Guerrilla. Combatientes chilenos en Colombia, El Salvador y Nicaragua. Santiago, Ceibo ediciones, 2017.

- Eugenia Palieraki, ;La revolución ya viene!. El MIR chileno en los años sesenta, Santiago, LOM, 2014.

-Cristián Pérez, "Compañeros, a las armas: combatientes chilenos en Centroamérica (1979-1989)",

Revista de Estudios Públicos, N 129, Centro de Estudios Públicos, Santiago, 2013.

- Julio Pinto Vallejos, Sebastián Leiva Flores, "Punto de quiebre: el MIR en los ochenta", en, Varios autores, Su revolución contra nuestra revolución. La pugna marxista-gremialista en los ochenta, Santiago, LOM, 2008.

-Pablo Pozzi, Claudio Pérez (ed.). Historia oral e Historia política. Izquierda y lucha armada en América Latina, 1960-1990. Santiago, LOM, 2012.

- Gustavo Rodríguez Ostria, "De la guerra de guerrillas al partido de cuadros: del ELN al PRT-B en Bolivia, 1967-1979. En Pablo Pozzi, Claudio Pérez (ed).

-Gustavo Rodríguez Ostria. Sin tiempo para las palabras. Teoponte. La otra guerrilla guevarista en Bolivia. Bolivia, Kipus, 2006.

- Luis Rojas Núñez. De la rebelión popular a la sublevación imaginada. Santiago, LOM, 2011. 
2) Fuentes digitales

-Centro de Estudios y Promoción del Desarrollo, Violencia Política en el Perú, 1980-1988. Perú, edición digital, www.lanic.utexas.edu, 1989.

- Raúl Mesa García. "El general chileno Pedro Vargas Sotomayor: maestro de mambises", Revista Sudhistoria, N 3, julio-diciembre, Valdivia, Universidad Austral de Chile, www.dialnet.unirioja.es, 2011.

-Manuel Requena Gallego, "Las Brigadas Internacionales: una aproximación historiográfica". Revista Ayer $\mathrm{N}^{\circ}$ 56, Universidad Autónoma de Madrid, www.ahistcon.org, 2004.

-Sergio Reyes, Compilador. "La Historia de Sergio Mancilla Caro, un Guerrillero Internacionalista Austral" edición digital, www.store.bookbaby.com, 2014.

- Luis Roniger y Pablo Yankelevich, "Exilio y política en América Latina: nuevos estudios y avances teóricos". Revista de Estudios Interdisciplinarios de América Latina y el Caribe. Número 1. Instituto Sverdlin de Historia y Cultura de América Latina, Universidad de Tel Aviv, www.dialnet.unirioja.es, 2009.

- Flora Tristán, Unión Obrera, en, Colección Socialismo y Libertad, Edición Digital, El Sudamericano, www.elsudamericano.wordpress.com, 2016

- Olga Ulianova. "A sesenta años de la guerra civil española. Combatientes chilenos en las brigadas internacionales", Revista de Estudios Avanzados, Volumen 5, Nº, IDEA-USACH, Santiago, ww2.educarchile.cl, 2006.

\section{3) Entrevistas}

-Daniel. Ricardo Antonio. Entrevista realizada el 10 de marzo de 2017 en la ciudad de Viña del Mar. Entrevistador: Pedro Valdés Navarro.

-Fermín. Entrevista realizada el 19 de enero de 2015 en la ciudad de Santiago. Entrevistador: Pedro Valdés Navarro.

-Rubén. Entrevista realizada el 14 de octubre de 2014 en la ciudad de Viña del Mar. Entrevistador: Pedro Valdés Navarro.

-Patricio. Entrevista realizada el 11 de junio de 2015 en la ciudad de Casablanca. Entrevistador: Pedro Valdés Navarro. 